\title{
Experimental Research on Fiber Filtration Wastewater of Oily Car Washing
}

\author{
Wensheng Lyu ${ }^{1, a}$, Zhaoxia Yin ${ }^{2, b^{*}}$, Ye Lyu ${ }^{3, c}$ and Pengchun $\mathrm{Hu}^{1, \mathrm{~d}}$ \\ ${ }^{1}$ Automotive and Architectural Engineering College of Beihua University Jilin Jilin China 132013 \\ ${ }^{2}$ Foreign Language College of Beihua University Jilin Jilin China 132013 \\ ${ }^{3}$ College of Foreign Languages in Northeast Forestry University Harbin Heilongjiang China 150000 \\ alwskytd@126.com, 'b941846596@qq.com, ‘2503086882@qq.com, d2844311831@qq.com \\ *The corresponding author
}

\section{Keywords: Fiber filtration; Oily wastewater; Ceramic sand; Fiber degreasing}

\begin{abstract}
Through the comparative experiments between fiber filter and ceramic sand filter, it confirms that the effect of fiber filter is obviously better than ceramic sand in dealing with oily washing wastewater. Fiber filter has features such as highly oil removal rate, long filtration period and large production of cycle. The experiment also confirms that putting PT $(1.0 \%)+\mathrm{NaCl}(2.0 \%)$ in the backwashing water will increase the oil removal rate. The effect of oil removal rate is the ideal when the water temperature is higher than 40 centigrade.
\end{abstract}

\section{Introduction}

Waste car- washed water contains complex varieties of oil and big fluctuation of oil content. Due to the use of anionic detergents in the car washing process, the oil in the water is mainly in the form of emulsified oil. At present, the treatment of oily wastewater mainly includes coagulation, filtration, air floatation, bioanalysis and membrane methods. [1]For the majority of small car washes, car washing wastewater process requires simple operations and small areas because of restrictions of car wash space and personnel managements.

Current filter technology commonly adopts ceramic sand which has better effects. But its speed is not high and covers a larger area. But Fiber filtration technology takes prominent advantages. [2] The fiexible material, polypropylene fiber filament, is applied in the research of fiber filtration technology. [3] Fiber filtration technology is of high filtration precision. The removal of suspended solids in water can be close to $100 \%$. Its filtration speed is three to five times faster than mechanical filtration. Besides that ceramic sand's capacity for interception of sewage is large $(5-10 \mathrm{Kg} / \mathrm{m} 3)$ and its area is small. The same amount of water covers only $1 / 3-1 / 2$ areas compared with traditional filter. What's more, its consumption is low which is only $1-3 \%$ of the periodical water production. The life of filter material is not less than 10 years so there doesn't exist the phenomenon such as spilling materials, compaction and so on.[4]

Considering the hydrophobic oil-wet characteristics of fiber [5] and the removal requirement of other pollutants in the oil washing waste water including silt, organics, detergents and etc, this paper begins by the contrast filtering experiment between fiber filter material and ceramic sand filter material taken from the oil waster water of small carwash. Then it studies the deoiling method about the fiber filter material in order to provide a feasible method for the disposing of oil washing waste water.

\section{Testing Apparatus}

Cistern: Used for coagulation precipitation. Size is to multiply one meter by 0.5 meter by 0.8 meter.

Filtration Column: Two filtration columns, diameter of 100 millimeter, height of 1600 millimeter. The operation is controlled by adjusting the valves. Fiber filter material and ceramic sand filter material will be padded into the filtration columns respectively. 
Fiber filter column: The total weight of fiber filter material is 408 grams and the swelling degree is $20 \%$. [6] Fiber filter material parameters are shown in table 1. Fiber bundle is fixed from the bottom and the upper is free [7]. Ceramic sand filter column: Fiber material and the matching are shown in Table 2.

Table 1 Main Technical Parameters of Fiber Filter[8]

\begin{tabular}{cccccc}
\hline Texture & Density & Length & $\begin{array}{c}\text { Weight-to- } \\
\text { Volume } \\
\text { Ratio }\end{array}$ & $\begin{array}{c}\text { Fiber } \\
\text { Diameter }\end{array}$ & $\begin{array}{c}\text { Swelling } \\
\text { Degree }\end{array}$ \\
\hline $\begin{array}{l}\text { Polypropylene } \\
\text { Fiber Filament }\end{array}$ & $0.91\left[\mathrm{~g} / \mathrm{cm}^{3}\right]$ & $1.3[\mathrm{~m}]$ & $160\left[\mathrm{~kg} / \mathrm{m}^{3}\right]$ & $50[\mu \mathrm{m}]$ & $20 \%$ \\
\hline
\end{tabular}

Table 2 Ceramic Sand Material and its Layer Matching

\begin{tabular}{lccccc}
\hline Filter Material & $\begin{array}{c}\text { Particle } \\
\text { Diameter } \\
\text { [mm] }\end{array}$ & $\begin{array}{c}\text { Effective } \\
\text { Particle } \\
\text { Diameter } \\
d_{10}[\mathrm{~mm}]\end{array}$ & $\begin{array}{c}\text { Nonuniform } \\
\text { Coefficient } \\
K_{80}\end{array}$ & $\begin{array}{c}\text { Equivalent } \\
\text { Particle } \\
\text { Diameter } \\
\text { [mm] }\end{array}$ & $\begin{array}{c}\text { Filter Layer } \\
\text { Thickness }\end{array}$ \\
\hline Ceramic Sand & $0.9-1.2$ & 1 & 1.1 & 1.08 & 900 \\
& & & & & \\
\hline
\end{tabular}

\section{Experimental Water}

The existence of other pollutants in washing waste water might influence the deoiling effect. In the consideration of such factor, all the experimental water is the waste water in the carwash collecting basin with the oleaginousness of 27.8 milligram per litre taken from the $4 \mathrm{~S}$ stores. After testing, the other water quality indicators are as follows. Turbitity is 364NTU, COD cris189 milligramper litre. LAS (anionicsurfactanis) 5.6 milligram per litre and PH is 7.8. Water temperature is 20 centigrade.

\section{Experiment Process and Results}

Coagulation Sedimentation. This experiment takes the poly aluminum chloride(PAC)as the experimental coagulant.[9] It carries on the coagulation-flocculation jar test to make sure that the PAC dosage of 70 milligram per litre will be better. When the oleaginousness of waterintake reached 27.8 milligram per litre, the oleaginousness of effluent is 17.0 milligram per litre, the coagulation precipitation on oil removal rate reaches to $39 \%$.

Filtration. Experimental method: The experiment is to filter the water which includes $17 \mathrm{mg} / \mathrm{L}$ oil after the process of coagulating and precipitating. It is conducted by comparing the filtering of the water through fiber material and ceramsite sand material by the rate of $9.8 \mathrm{~m} / \mathrm{h}$, then repeats the experiment by the rate of $15.6 \mathrm{~m} / \mathrm{h}$. It is because that the filtration cycle is determined by the amount of pollutant and affected by the filtration rate, the filtration cycle of fiber material is recognized as 8 hours and the filtration cycle of ceramsite sand material is recognized as 8 hours and 4 hours by the rate of $9.8 \mathrm{~m} / \mathrm{h}$ and $15.6 \mathrm{~m} / \mathrm{h}$ respectively in order to ensure the experiment effect.

After 8 hours and 4 hours by the filtration rate of $7.8 \mathrm{~m} / \mathrm{h}$ and $15.6 \mathrm{~m} / \mathrm{h}$ respectively the ceramsite sand material should be backflushed by rinsing, which lasts 8 minutes and the intensity of backwash is $6 \mathrm{~L} /\left(\mathrm{s} \cdot \mathrm{m}^{2}\right)$. After 8hours the fiber material goes through air-water backwashing in which the intensity of compressing air is $10 \mathrm{~L} /\left(\mathrm{s} . \mathrm{m}^{2}\right)[10]$ and the time and intensity of back wash is the 
same as Ceramsite sand material. After three cycles of the experiment it is needed to take the average of the statistics.

The result of the experiment can be shown in table 3. It can be seen that the rate of removing oil is almost the same in the low filtration rate and the effect of Ceramsite sand material is slightly better than that of fiber material. When the filtration rate doubles, the rate of removing oil caused by fiber material is higher than that by ceramsite sand material and fiber material has long filtration cycle and big output. With the increasing of filtration rate, the ceramsite sand material has short filtration cycle which is half of that of the fiber material and low rate of removing oil.

Table 3 The Comparison of the Effect Between Fiber Material and Ceramsite Sand Material

\begin{tabular}{cccccc}
\hline & $\begin{array}{c}\text { Filtration } \\
\text { rate[m/h] }\end{array}$ & $\begin{array}{c}\text { The oil in filtered } \\
\text { water[mg/L] }\end{array}$ & Removal rate\% & $\begin{array}{c}\text { Filtration } \\
\text { cycle[h] }\end{array}$ & $\begin{array}{c}\text { Periodic water } \\
\text { yield } \\
{\left[\mathrm{m}^{3]}\right.}\end{array}$ \\
\hline \multirow{2}{*}{ Fiber } & 7.8 & 9.0 & 41.1 & 8 & 0.490 \\
& 15.6 & 11.1 & 34.7 & 8 & 0.980 \\
$\begin{array}{c}\text { Ceramsi } \\
\text { te }\end{array}$ & 7.8 & 9.8 & 42.4 & 8 & 0.490 \\
\hline
\end{tabular}

The Cleaning and Deoiling of Fiber Material. According to some related research results it is ideal to do the experiment of deoiling and regeneration of polypropylene fiber when the anionic surfactant which contains sulfonic acid group (PT), $\mathrm{NaCl}$ or $\mathrm{NaOH}$ and water mixed at the mass of $0.1 \mathrm{~g}$ to $1.0 \mathrm{~g}, 2.0 \mathrm{~g}$ or $1.5 \mathrm{~g}$ and $100 \mathrm{~g}$ in the water whose degree is more than $40{ }^{\circ} \mathrm{C}$.[11]

Experiment method:

This experiment adopted three back washing water including: A: water $\left(20{ }^{\circ} \mathrm{C}\right)$; $\mathrm{B}$ : water $\left(20{ }^{\circ} \mathrm{C}\right)$, PT (the solute is 1 percent of the solution) and sodium chloride (the solute is 2 percent of the solution); C: water $\left(40^{\circ} \mathrm{C}\right)$, PT (the solute is 1 percent of the solution) and sodium chloride (the solute is 2 percent of the solution)

First of all the new fiber materials we have mentioned above which weight 408 gram is chosen to put into the filtration column. The raw water which contains $27.8 \mathrm{mg} / \mathrm{L}$ is poured into the filtration device and is filtered by the rate of $15.6 \mathrm{~m} / \mathrm{h}$ and in the filtration cycle of 8 hours. The experiment stops after one filtration cycle, and the test of oleaginousness after filtering raw water and the calculation of the oil quantity filtered by fiber material are shown in Table 4.

Table 4 The Calculation of the Oil Quantity Filtered by Fiber Material

\begin{tabular}{cccc}
\hline $\begin{array}{c}\text { Oil quantity in inflow } \\
\text { water }[\mathrm{mg} / \mathrm{L}]\end{array}$ & $\begin{array}{c}\text { Oil quantity in } \\
\text { filtered water } \\
{[\mathrm{mg} / \mathrm{L}]}\end{array}$ & $\begin{array}{c}\text { Water quantity } \\
\text { needed to be } \\
\text { filtered }\left[\mathrm{m}^{3}\right]\end{array}$ & $\begin{array}{c}\text { oil quantity caught by } \\
\text { fiber material [mg] }\end{array}$ \\
\hline 27.8 & 18.9 & 0.980 & 8722 \\
\hline
\end{tabular}

Then taking out the experimental fiber filtering material without backwashing from filter candle, drain water, divide into 3 equal parts, and each fiber is $136 \mathrm{~g}$, oil quantity is $2907 \mathrm{mg}$. Every time a bundle of fibers is lay back into the filter candle for experiment, the installation method of fiber bundle is still fixed at base, free end at top. Backwashing water enter from the bottom, and top ends discharge, the backwashing method is same as the previous method, the water consumption for each time backwashing is $22.6 \mathrm{~L}$. Backwashing oleaginousness discharges were respectively calculated: the oil removal effect of washing water $\mathrm{A}$ is poor, the washing water $\mathrm{B}$ is better, while the washing water $\mathrm{C}$ has the best oil removal effect, in Table 5. 
Table 5 Comparison of the Oil Removal Effect among Three Kinds of Washing Methods on Fiber Filter Material

\begin{tabular}{cccc}
\hline & $\begin{array}{c}\text { Oil content of } \\
\text { discharging backwashing } \\
\text { water } \\
{[\mathrm{mg} / \mathrm{L}]}\end{array}$ & $\begin{array}{c}\text { Oil removal } \\
\text { content } \\
{[\mathrm{g}]}\end{array}$ & $\begin{array}{c}\text { Oil removal rate } \\
\%\end{array}$ \\
\hline washing water A & 88.5 & 2.000 & 68.8 \\
washing water B & 104.8 & 2.369 & 81.5 \\
washing water C & 126.6 & 2.860 & 98.4 \\
\hline
\end{tabular}

\section{Conclusion}

Fiber filter material is characterized high oil removal rate, prolonging filtration and large periodic water yield, which can be an optimum replacement of the filtration process of oil car-washing water.

Fiber filter material has hydrophobic and lipophilic characteristics, the simple backwashing water cannot realize effective oil removal, the backwashing water is added into PT $(1.0 \%)+\mathrm{NaCl}$ (2.0\%) will improve the oil removal rate, under the water temperature $>40^{\circ} \mathrm{C}$ has the most ideal result.

Due to the fiber filter has better effect on suspended solids, which is beneficial to subsequent advanced treatment process, and fast filter speed, smaller area occupied, long working life, making it possible for the miniaturization of car-washing wastewater treatment equipment.

The fiber filter material need to be removed oil by using medicament without day, and air-water backwashing; the operation is relatively complex, needs for improving in future research.

\section{Acknowledgements}

This project is the scientific and technology research for the provincial department of education in Jilin. Item No.138, 2015.

\section{References}

[1] F.Y. Cui,L. Tang and B.L. Wu,Oil Removal in Car Wash Wastewater Treatment for Rescues, Water \& Wastewater Engineering, Vol.31 (2005) No.11,P.61-64.(in Chinese)

[2] Y.F. Jiang, L.Wang, B.Z.Wang etal, A study on Reclamation of Secondary Effluent by Fiber Filtration. Techniques and Equipment for Environmental Pollution Control, Vol.6 (2005) No. 12, P97-100. (In Chinese)

[3] F.Q. Liu, Medium Filtering Methods and Equipments. P.R.C. Patent ZL87100467. (1987).

[4] W.Y. Zhang, L.J. Xi, X.M. Chen etal, Working Principles and Features of Several Fiber Filter Equipments China Water Supply and Sewerage, Vol.19 (2003) No.6,P. 23-25.(In Chinese)

[5] Y.X. Yang,Z.S. Wang and X.J.Zhang, Improvement of Oil-Proof Capability of Fiber Ball Filtration Medium by Oil Field Wastewater, Water\& Wastewater Engineering, Vol. 27 (2001) No.3,P.48-51.(In Chinese)

[6] S.P. Yuan, M.L. Zhao and F.L. Yu, Experimental Study on Influence of Fiber Pulling Degree on Filtration, Industrial Water and Wastewater, Vol.37 (2005) No.4,P.71-73. (In Chinese)

[7] W.C. Cheng, Fiber Filter Equipments. P.R.C. Patent ZL98246416.9 (1998)

[8] W.S. Lyu, The Technical Parameter of the Self-adjusted Fiber-filtering Value Engineering, Vol.30 (2011) No.6,P.40.(in Chinese) 
[9] K.Xu, Application of High Quality Polyaluminium Chlorideinre Claimation Treatment of Petroleum-Chemical Wastewater Environmental Chemistry, Vol.15 (2005) No.4, P.356-359. (in Chinese)

[10]F. Zhou,Sh.H. Wang, H. Zhao etal, Backflushing Characteristics of Highly Effective Filter with Long Fiber Technology of Water Treatment, Vol.32 (2006) No.5,P.1422.(in Chinese)

[11]Z.Wu, F.Q.Liu and L.J.Xi,The Study of Surfactant Removing Oil from the Surface of Hydrophobic Fiber Industrial Water Treatment, Vol. 1 (2000) No. 1,P.22-24.(in Chinese) 